\title{
Inclusion Polymerization in Polymorphic Crystals of Cholic Acid
}

\author{
Kazunori NAKANo, Kazuki SADA, ${ }^{*}$ and Mikiji Mryata ${ }^{*}{ }^{\dagger}$ \\ Nagoya Municipal Industrial Research Institute, 3-4-41 Rokuban, \\ Atsuta-ku, Nagoya 456-0058, Japan \\ ${ }^{*}$ Department of Material and Life Science, Graduate School of \\ Engineering, Osaka University, 2-1 Yamadaoka, Suita, Osaka 565-0871, Japan
}

(Received September 5, 2000; Accepted October 28, 2000)

\begin{abstract}
Inclusion polymerization of vinyl and diene monomers was studied using cholic acid (CA) as host. Polymorphism of CA inclusion crystals was found to play a decisive role in the polymerizability of the monomers. Polymorphic crystals were obtained by recrystallization and guest-exchange on intercalation. In the case of methacrylonitrile, CA forms two crystal structures; a bilayer structure with one-dimensional channels and crossing structure with cagelike cavities. The former structure is suitable for polymerization, but not the latter. In the case of 2,3-dimethyl-1,3butadiene, intercalation yielded only bilayer crystals. The microstructure of the resulting polymer was compared with those of the polymers obtained by other steroidal hosts. Different stereoregularity may be explained on the basis of different channel sizes of hosts.

KEY WORDS Inclusion Polymerization / Cholic Acid / Polymorphic Crystals / Channels / Methacrylonitrile / 2,3-Dimethyl-1,3-butadiene / Space Effect /
\end{abstract}

Many efforts have been devoted to the control of polymerizability on the basis of molecular assemblies, such as membranes, ${ }^{1}$ liquid crystals, ${ }^{2}$ gels, ${ }^{3}$ or crystals. ${ }^{4}$ In these assemblies, monomers are arrayed in a specific direction by noncovalent interactions, such as hydrogenbonding and van der Waals interaction, to give characteristic polymers. In particular, some solid-state polymerizations provide clear relations between the orientation of monomers and stereoregularity of the resulting polymers. 4

Inclusion compounds are useful assemblies for controlling the orientation of monomer molecules. ${ }^{5}$ Nanometer-level spaces of the compounds force guest molecules to be arranged in a specific direction. If the arrangements of various monomers are retained during polymerization, polymers with highly controlled stereochemical structures may be obtained. So far, successful examples are known for only limited combinations of hosts and monomers. New hosts suitable for such polymerization using inclusion compounds should thus be found.

Urea, thiourea, and perhydrotriphenylene are primary hosts for inclusion polymerization. These hosts yield highly stereoregular polymers from a limited range of diene monomers. ${ }^{6-9}$ A pair of steroidal hosts, deoxycholic acid (DCA) and apocholic acid (ACA), were adopted to evaluate the polymerizability of comprehensive diene monomers on the basis of relative space effects at the nanometer level. ${ }^{5,10-12}$ Methyl cholate (MCA) and chenodeoxycholic acid (CDCA), were confirmed to serve as hosts for inclusion polymerization. ${ }^{13-15}$

We earlier reported cholic acid (CA) to form inclusion crystals with various organic substances. X-Ray diffraction studies clarified that the crystals have bilayer structures with channels, as in the case of DCA and ACA. ${ }^{16}$ We so far have not proved that polymerization takes

\footnotetext{
${ }^{\dagger}$ To whom correspondence should be addressed.
}

place in CA channels. This was explained by the fact that CA crystals exhibit different polymorphism and dynamics from DCA and ACA. ${ }^{16-19}$ Systematic studies made clear that such polymorphism is guest- and/or environment-dependent, leading to decisive evidence supporting that inclusion polymerization proceeds even in CA channels. This paper deals with inclusion and polymerization of vinyl and diene monomers in CA crystals. Host lattices of CA often isomerize in response to structural and steric requirement of guest molecules. ${ }^{16}$ CA forms two-component polymorphs consisting of the same host-guest complex with the same stoichiometry. ${ }^{20,21}$ The effects of these polymorphic crystals are discussed in detail.<smiles>[R]CCC(C)C1CCC2C3C([R])CC4C[C@@H](O)CC[C@]4(C)C3CC([R])[C@@]12C</smiles>

Cholic acid (CA)

Deoxycholic acid (DCA) $; \mathrm{R}^{1}=\mathrm{OH} \mathrm{R}{ }^{2}=\mathrm{OH} \mathrm{R}{ }^{3}=\mathrm{CO}_{2} \mathrm{H}$

Chenodeoxycholic acid (CDCA); $\mathrm{R}^{1}=\mathrm{OH} \mathrm{R} \mathrm{R}^{2}=\mathrm{H} \mathrm{R}^{3}=\mathrm{CO}_{2} \mathrm{H}$ Methyl cholate (MCA) ; $\mathrm{R}^{1}=\mathrm{OH} \mathrm{R} \mathrm{R}^{2}=\mathrm{OH} \mathrm{R}{ }^{3}=\mathrm{CO}_{2} \mathrm{CH}_{3}$<smiles>CC1CCC(=O)OCCC2=C3CCC4C[C@@H](O)CC[C@]4(C)C3C[C@H](O)[C@]21C</smiles>

Apocholic acid (ACA)

Scheme 1. 


\section{EXPERIMENTAL}

\section{Formation of Inclusion Crystals}

All compounds were commercially obtained and used without purification. Polymorphic crystals of CA were obtained by recrystallization and intercalation. In the case of acrylonitrile and methacrylonitrile (MAN), crossing-type inclusion crystals of CA were prepared by direct recrystallization. CA (100 mg) was dissolved with warming in the liquid guest $(12 \mathrm{~mL})$, and the resulting solution was allowed to stand at room temperature. Channel-type inclusion crystals of CA with acrylonitrile, MAN, 2-chloroacrylonitrile, vinyl acetate, and 2,3dimethyl-1,3-butadiene (DMB) were prepared by intercalation: starting inclusion crystals $(100 \mathrm{mg})$ were obtained by direct recrystallization from acetophenone and $n$-propylbenzene, and soaked in liquid guest $(1 \mathrm{~mL})$ and allowed to stand at room temperature for seven days.

\section{Inclusion Polymerization}

The inclusion crystals (ca. $500 \mathrm{mg}$ ) were placed in a glass tube $10 \mathrm{~mm}$ in diameter and sealed under vacuum. The tube was exposed to $\gamma$-irradiation from a ${ }^{60} \mathrm{Co}$ source at $0^{\circ} \mathrm{C}$ for one hour at $1.0 \mathrm{Mrad}$. After irradiation, the tube was allowed to stand at room temperature for one day. The contents were poured into excess methanol to separate the polymer from CA. The methanol-insoluble fraction was filtered, dried under vacuum and weighed.

\section{Measurements}

Infrared spectra were recorded on a JASCO IRReport-100 spectrometer. ${ }^{1} \mathrm{H}$ NMR spectra were measured at $100^{\circ} \mathrm{C}$ with $\mathrm{JEOL} 270 \mathrm{MHz}$ spectrometer. Differential scanning calorimetry (DSC) and thermal gravimetry (TG) were performed on a Rigaku TAS 100 system. About $10 \mathrm{mg}$ crystals were heated from 40 to $230^{\circ} \mathrm{C}$ at $5^{\circ} \mathrm{C} \min ^{-1}$. X-Ray powder diffraction was recorded using a Rigaku RINT-2000 with $\mathrm{Cu}-K_{\alpha}$ radiation at room temperature. Diffraction patterns of $2 \theta\left(^{\circ}\right)$ angle with relative intensity in parenthesis are as follows.

$\mathrm{CA} \cdot \mathrm{MAN}$ (crossing type): 7.21(21), 9.57(32), 11.18(23), 12.47(11).

CA $\cdot$ MAN (bilayer type): 7.44(100), 8.28(5), 11.26(2), 12.96(2).

$\mathrm{CA} \cdot \mathrm{MAN}$ (bilayer type, after $\gamma$-irradiation): 7.07(31), 7.49(100), 8.35(8), 11.33(2), 13.02(6).

CA 2-chloroacrylonitrile: 7.45(44), 8.35(30), 11.23(5), $13.00(22)$.

CA - vinyl acetate: 7.57(100), 8.49(10), 11.19(3), 13.04(8).

CA.DMB: $7.20(10), 8.36(58), 10.88(1), 13.04(21)$.

$\mathrm{CA} \cdot \mathrm{DMB}$ (after $\gamma$-irradiation): 7.20(24), 8.32(43), 10.84 (3), 13.00(20).

Average molecular weight and molecular weight distribution of polymers were measured by a modular system for gel permeation chromatography (GPC) consisting of a Shodex Degas, JASCO Model 880-PU solvent delivery system, Shodex Model AO-50 injector and column oven system, and Shodex RI SE-61 differential refractometer interfaced with a System Instruments Chromatocorder 12. AC-803 and AC-80 M Columns and polystyrene standards were from Showa Denko K.K.

\section{Molecular Graphics}

A molecular graphics study was carried out using computer software based on MODRASTE. ${ }^{22}$ Atomic radii of hydrogen, carbon, and oxygen in the cross-sectional views were $1.20 \AA, 1.60 \AA$, and $1.45 \AA$, respectively.

\section{RESULTS AND DISCUSSION}

\section{Polymorphic Inclusion Crystals of CA with Vinyl Mono- mers}

CA forms many guest-dependent polymorphic crystals. A typical crystal has a crossing structure with cagelike cavities or bilayer structure with one-dimensional cavities, called channels, as shown in Figure 1. A guest component usually adopts only one structure, but the same guest component may induce multiple polymorphic crystals. Therefore, we carefully tested preparation of the crystals by direct recrystallization and intercalation or guest-exchange. In the former, addition of a third component may change crystal structure. In the latter, CA crystals may retain or change crystal structure during absorption or exchange of guest molecules.

The same guest gave crossing and bilayer structures by recrystallization in the presence of a third component. ${ }^{20,21}$ Recrystallization of CA from liquid acrylonitrile and methacrylonitrile (MAN) yielded the former crystals with the same 1:1 molar ratio of host to guest. Recrystallization using an alcohol as the third component gave the latter crystals with nitriles.

Intercalation easily afforded the latter channel-type crystals. At first, inclusion crystals of CA with acetophenone $(\mathrm{AP})^{23}$ were prepared by recrystallization, and the crystals were soaked in MAN for seven days. XRay diffraction of $\mathrm{CA} \cdot \mathrm{AP}$ crystals slightly changed to that of channel-type $\mathrm{CA} \cdot \mathrm{MAN}$ crystals from recrystallization, as shown in Figure 2. Instead of CA AP crystals, when inclusion crystals of CA with ethanol were used as original crystals, guest-exchange did not occur. This would be due to host lattice types of the original crystals. Since CA ethanol crystals have a crossing structure with cage-like cavities, ${ }^{24}$ exchange to $\mathrm{CA} \cdot \mathrm{MAN}$ crystals requires dynamic change of the host lattice with hydrogen bond networks. CA AP crystals have a channel-type structure, so that exchange occurs with retention of the host lattice to yield CA-MAN crystals. The channel-type crystals of $\mathrm{CA} \cdot \mathrm{MAN}$ were so stable that they did not

(a)

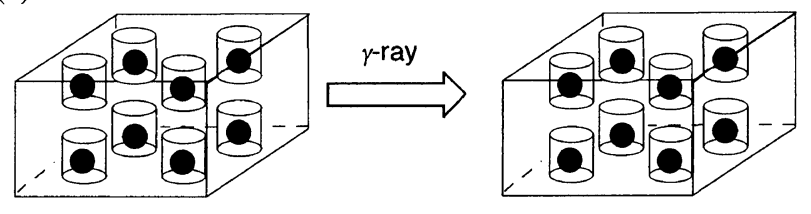

(b)

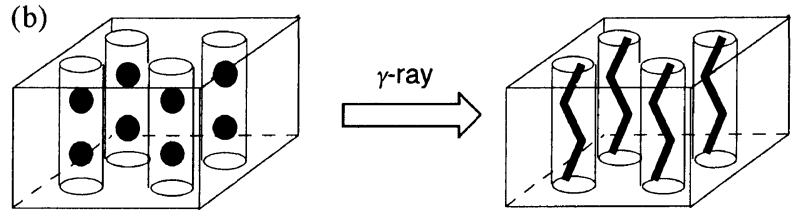

Figure 1. CA crystals of (a) crossing structure with cage-like cavities and (b) bilayer structure with channel cavities. 
Table I. Inclusion polymerization of vinyl and diene monomers

\begin{tabular}{lccccc}
\hline \multicolumn{1}{c}{ Monomer } & Method $^{\mathrm{a}}$ & Inclusion space & Yield $/ \%^{\mathrm{b}}$ & $M_{\mathrm{n}} / \times 10^{4 \mathrm{c}}$ & $M_{\mathrm{w}} / M_{\mathrm{n}}^{\mathrm{c}}$ \\
\hline Methacrylonitrile & $\mathrm{R}$ & Cage & 0 & - & - \\
Methacrylonitrile & $\mathrm{E}$ & Channel & 34 & 15 & 3.2 \\
2-Chloroacrylonitrile & $\mathrm{E}$ & Channel & 26 & 0.48 & 2.3 \\
Vinyl acetate & $\mathrm{E}$ & Channel & 0 & - & - $^{\mathrm{d}}$ \\
2,3-Dimethylbutadiene & $\mathrm{E}$ & Channel & 34 & $\mathbf{C}^{\mathrm{d}}$ \\
\hline
\end{tabular}

${ }^{\mathrm{a}} \mathrm{R}=$ Recrystallization, $\mathrm{E}=$ Guest-exchange. ${ }^{\mathrm{b}}$ Methanol-insoluble fractions were weighted. ${ }^{\mathrm{c}} M_{\mathrm{w}}$ and $M_{\mathrm{n}}$ are based on the calibration of standard polystyrene. ${ }^{\mathrm{d}}$ Not determined due to insoluble polymers.

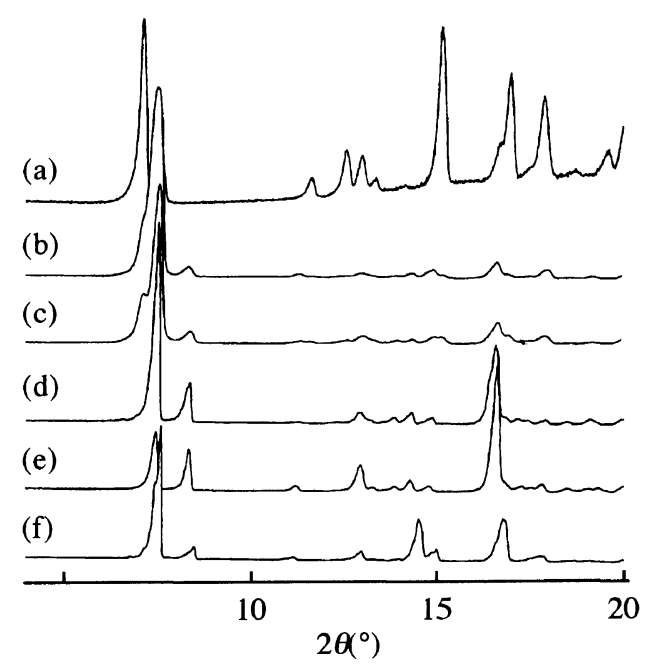

Figure 2. X-Ray diffraction patterns of inclusion compounds of (a) $\mathrm{CA} \cdot \mathrm{AP}$ obtained by recrystallization, (b) guest-exchanged $\mathrm{CA}$. MAN, (c) guest-exchanged CA·MAN after $\gamma$-irradiation, (d) channel-type CA $\cdot \mathrm{MAN}$ obtained by recrystallization, (e) CA 2 chloroacrylonitrile, and (f) $\mathrm{CA} \cdot$ vinyl acetate.

transform to crossing type for months. In contrast, the channel-type crystals of CA-acrylonitrile were unstable and transformed to the crossing type, meaning that the crystals were not suitable for inclusion polymerization.

\section{Inclusion Polymerization of Vinyl Monomers}

The incorporation of identical monomers in different inclusion spaces prompted us to examine cavities as reaction spaces for inclusion polymerization. The polymerization of the two types of $\mathrm{CA} \cdot \mathrm{MAN}$ crystals was carried out in a similar way to other steroidal hosts. ${ }^{10-15}$ The results are summarized in Table I. Polymers were obtained from crystals having channels but not cage-like cavities. As shown in Figure 1, monomers in cage-like cavities cannot react with adjacent monomers owing to hindrance of host molecules. The different results for the same host and the monomer prove that polymerization occurs in channels not outside crystals. The resulting polymers had no significant differences in microstructures from polymers obtained by free-radical polymerization in solution. Polymerization in channels was confirmed by X-Ray powder diffraction. Comparison of diffraction of CA.MAN crystals before and after $\gamma$ irradiation showed they were very similar, as shown in Figure 2. The channel structure is thus maintained during polymerization.

Inclusion polymerization of 2-chloroacrylonitrile and vinyl acetate was examined. The crystals had similar patterns to that of CA $\cdot$ MAN crystals, as shown in Figure

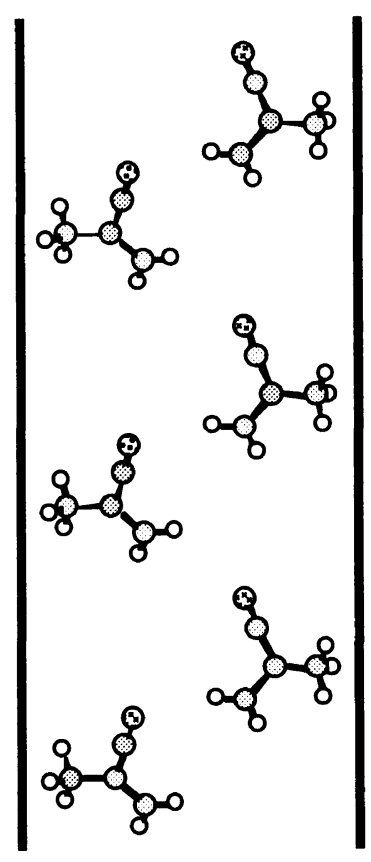

Figure 3. Arrangement of MAN molecules in a CA channel. Carbon, hydrogen, and nitrogen atoms are represented in gray, white, and dotted, respectively.

2 , indicating that the two monomers are incorporated into channels like MAN molecules. $\gamma$-Irradiation generated the polymers from inclusion crystals of $\mathrm{CA} \cdot 2$ chloroacrylonitrile, but not of $\mathrm{CA} \cdot$ vinyl acetate, due to different arrangements of monomers in the channels.

Figure 3 shows an arrangement of MAN molecules in a CA channel, where $-\mathrm{C}=\mathrm{C}$ - double bond moieties of MAN molecules lie in the center of the channel. Similar arrangement may be achieved by 2 -chloroacrylonitrile molecules because of the similar molecular structure with MAN, while vinyl acetate molecules may have no suitable arrangement for the reaction. Inclusion polymerization may thus require not only channel structures but also appropriate arrangements of included monomers in the channels.

\section{Inclusion Polymerization of Diene Monomer}

As in the case of channel-type crystal of CA-MAN, inclusion compounds of $\mathrm{CA}$ with 2,3-dimethyl-1,3butadiene (DMB) were prepared by guest-exchange. When inclusion crystals of CA with $n$-propylbenzene ${ }^{15}$ were used as original crystals, CA-DMB crystals were easily obtained. TG-DSC measurement confirmed that inclusion crystals have $1: 1$ host-guest stoichiometry. When inclusion crystals of $\mathrm{CA} \cdot$ ethanol were used as original crystals, guest-exchange did not occur as in the 


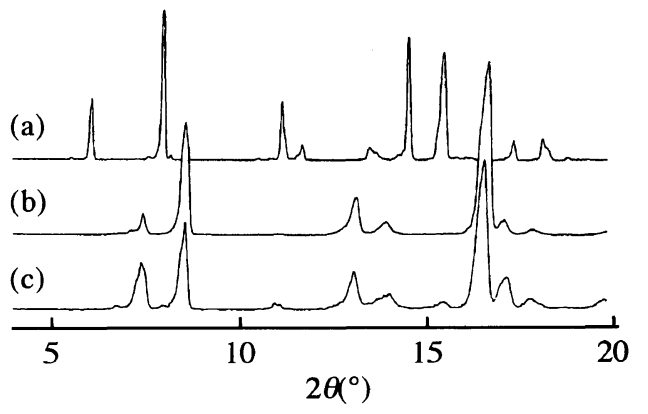

Figure 4. X-Ray diffraction patterns of inclusion compounds of (a) $\mathrm{CA} \cdot n$-propylbenzene, (b) guest-exchanged $\mathrm{CA} \cdot \mathrm{DMB}$, and (c) guest-exchanged $\mathrm{CA} \cdot \mathrm{DMB}$ after $\gamma$-irradiation.

case of CA $\cdot$ MAN. Even channel-type crystals, such as $\mathrm{CA} \cdot \mathrm{AP}$ and $\mathrm{CA} \cdot \gamma$-valerolactone, ${ }^{25}$ did not give guestexchanged $\mathrm{CA} \cdot \mathrm{DMB}$ crystals. Guest-exchange may be attributed to the channel size; $\mathrm{CA} \cdot n$-propylbenzene crystals have larger cavities than $\mathrm{CA} \cdot \mathrm{AP}$ and $\mathrm{CA} \cdot \gamma$ valerolactone crystals. The larger cavities would lead to guest-exchange to give CA-DMB crystals easily. Appropriate original crystals should be thus selected to obtain inclusion crystals with monomers.

$\mathrm{X}$-Ray powder diffraction revealed that the structures of the resulting $\mathrm{CA} \cdot \mathrm{DMB}$ crystals were completely different from the original. As shown in Figure 4, the resulting crystals have channel-type structures similar to CA $\cdot$ MAN crystals. Diffraction peaks of guest-exchanged $\mathrm{CA} \cdot \mathrm{DMB}$ crystals are similar to those after $\gamma$ irradiation, indicating that polymerization proceeds with retention of channel-type structures.

$\gamma$-Irradiation of $\mathrm{CA} \cdot \mathrm{DMB}$ crystals led to solid poly$\mathrm{DMB}$ as in the case of DCA and ACA, or rubber-like polymers as with MCA and CDCA. The IR of the polymer had a strong absorption band at $1150 \mathrm{~cm}^{-1}$ characteristic of 1,4-addition, whereas tiny bands at $1630 \mathrm{~cm}^{-1}$ and $890 \mathrm{~cm}^{-1}$ characteristic of 1,2 -addition. In the ${ }^{1} \mathrm{H}$ NMR spectrum, methylene resonance appeared at 2.24 ppm for the 1,4-cis-addition and $2.16 \mathrm{ppm}$ for the 1,4trans-addition, and tiny peaks for the 1,2-addition appear at 4.85 and $4.90 \mathrm{ppm}$ corresponding to the double bond. ${ }^{26}$ This shows that the polymer contained $52 \%$ of 1,4-trans-addition, $44 \%$ of 1,4-cis-addition, and $4 \%$ of 1,2-addition.

\section{Comparison with Other Steroidal Hosts}

Space effects of CA channel may be found on the basis of the microstructure of poly-DMB obtained using steroidal hosts. As shown in Table II, stereoregularity of the polymer in the case of CA is much lower than with DCA, ACA, and MCA, but slightly higher than with CDCA. In spite of similar stereoregularity of the polymers from CA and CDCA, solubility for organic solvents differed; the polymer from CDCA was easily soluble in tetrahydrofuran, but not the polymer from CA.

Difference in the stereoregularity may be understood by comparison with channel size of each host. Host lattices of four steroidal hosts, DCA, ACA, CA, and CDCA, for $\mathrm{DMB}$ differ each other, ${ }^{20,27-29}$ whereas the host lattice of MCA.DMB is unknown due to the guestdependent structure. ${ }^{14}$ Figure 5 shows cross sections of four host channels sliced perpendicular to the direction
Table II. Microstructure of poly-DMB obtained using steroidal hosts

\begin{tabular}{lcccl}
\hline Host & $\begin{array}{l}\text { 1,4-trans } \\
\text {-addition/\% }\end{array}$ & $\begin{array}{c}1,4 \text {-cis } \\
\text {-addition/\% }\end{array}$ & $\begin{array}{l}1,2 \\
\text {-addition/\% }\end{array}$ & Reference \\
\hline DCA & $>99$ & 0 & 0 & 10 \\
ACA & $>99$ & 0 & 0 & 12 \\
MCA & 90 & 10 & 0 & 13,14 \\
CA & 54 & 42 & 4 & This work \\
CDCA(None) & 54 & 38 & 8 & $15,(26)$ \\
\hline
\end{tabular}
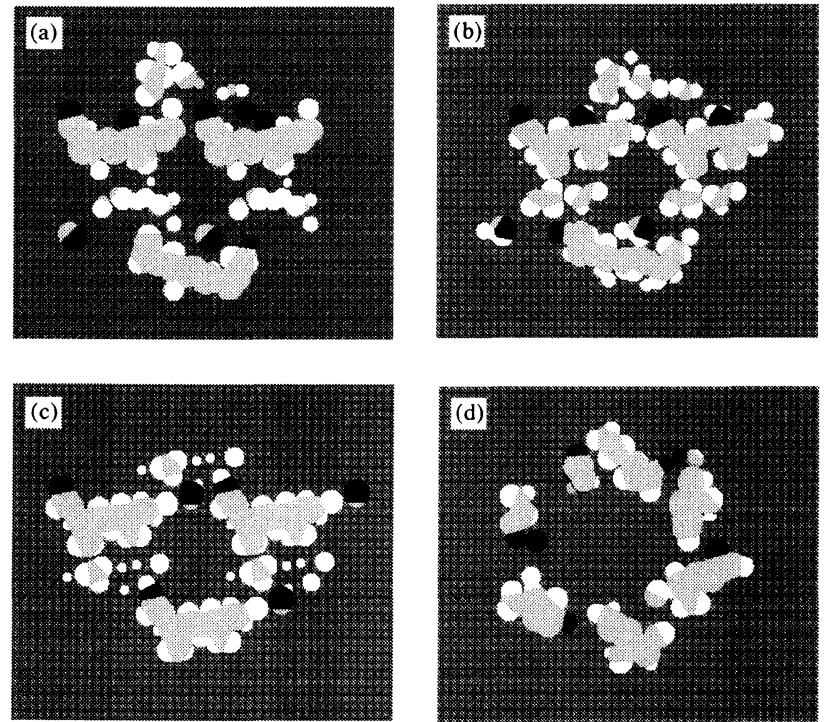

Figure 5. Cross sections of steroidal host channels sliced perpendicular to direction of the channel of (a) DCA, (b) ACA, (c) CA, and (d) CDCA. Guest molecules are omitted. Carbon, hydrogen, and oxygen atoms are represented in gray, white, and black, respectively.

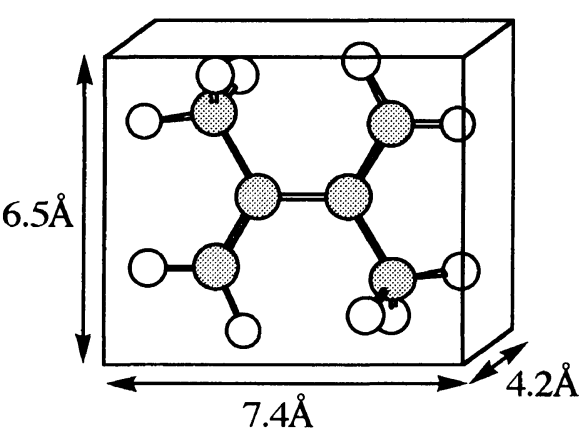

Figure 6. Shape of a DMB molecule based on molecular modeling. Atom coding is identical to that in Figure 3.

of the channels. Cross sections of host cavities of DCA, ACA, CA, and CDCA, were nearly a $8 \times 3.5 \AA$ square, 6.5 $\AA$ in diameter, $8 \AA$ in diameter, and $12 \AA$ in diameter, respectively.

The shape of the DMB molecule is nearly a $7.4 \times 6.5 \times$ $4.2 \AA$ box, as estimated from geometrical calculation from molecular models, as shown in Figure 6. The microstructures of obtained polymers thus agree with channel size. The narrow channels of DCA and ACA would just fit DMB molecules and force them to be arranged in a specific direction. In contrast, the DMB molecules may move freely in CDCA channel as in solution. In a 
medium-size CA channel, DMB molecules move with restriction of direction. Although the host lattice of MCA $\mathrm{DMB}$ is unknown as described above, the lattice may have one-dimensional cavities smaller than those of CA but larger than those of ACA.

\section{CONCLUSION}

This study demonstrates the first inclusion polymerization using CA. As with other steroidal hosts, the monomers can be incorporated into CA channel to give polymers. The stereoregularity of the resulting polymers was in good agreement with channel sizes of host lattices.

Inclusion polymerization using CA may be achieved by control of host lattice types of the monomer-included crystals because of polymorphism and dynamic properties of CA crystals. Polymorphic host lattices are observed in other hosts and are substantial properties of organic host compounds because their host lattices are maintained by noncovalent bonds. This study should promote further research on inclusion polymerization using other hosts.

Acknowledgment. The authors thank the Radiation Laboratory, Institute of Scientific, and Industrial Research, Osaka University, for allowing use of ${ }^{60} \mathrm{Co}$ facilities. This work was supported by Grants in Aid for Scientific Research from the Ministry of Education, Science, Sports, and Culture, Japan (Priority Area, Dynamic Control of Stereochemistry).

\section{REFERENCES}

1. H. Ringsdorf, B. Schlarb, and J. Venzmer, Angew. Chem., Int. Ed. Engl., 27, 113 (1988).

2. C. A. Guymon, E. N. Hoggan, N. A. Clark, T. P. Rirker, D. M. Walba, and C. N. Bowman, Science, 275, 57 (1997).

3. M. Loos, J. Esch, I. Stokroos, R. M. Kellog, and B. L. Feringa, J. Am. Chem. Soc., 119, 12675 (1997).

4. A. Matsumoto, T. Odani, M. Chikada, K. Sada, and M. Miyata, J.Am. Chem. Soc., 121, 11122 (1999).

5. M. Miyata, "Inclusion Polymerization" in "Comprehensive Supramolecular Chemistry", D. Reinhoudt, Ed., Pergamon, Oxford, 1996, vol. 10, pp 557-582.
6. J. F. Brown, Jr. and D. M. White, J. Am. Chem. Soc., 82, 5671 (1960).

7. D. M. White, J. Am. Chem. Soc., 82, 5678 (1960).

8. M. Farina, G. Natta, G. Allegra, and M. Löffelholz, J. Polym. Sci., C, 16, 2517 (1967).

9. M. Farina, G.Audisio, and M. T. Gramegna, Macromolecules, 5, 617 (1972).

10. M. Miyata, K. Morioka, and K. Takemoto, J. Polym. Sci., Polym. Chem. Ed., 15, 2987 (1977).

11. M. Miyata, T. Tsuzuki, F. Noma, and K. Takemoto, Makromol. Chem. Rapid Commun., 9, 45 (1988).

12. M. Miyata, Y. Kitahara, Y. Osaki, and K. Takemoto, J. Inclusion Phenom., 2, 391 (1984).

13. W. Goonewardena, M. Miyata, and K. Takemoto, Polym. J., 23, 1405 (1991)

14. W. Goonewardena, M. Miyata, and K. Takemoto, Polym. J., 25, 1405 (1993).

15. M. Chikada, K. Sada, and M. Miyata, Polym. J., 31, 1061 (1999).

16. M. Miyata and K. Sada, "Deoxycholic Acid and related Hosts" in "Comprehensive Supramolecular Chemistry", D. D. MacNicol, F. Toda, and R. Bishop, Ed., Pergamon, Oxford, 1996, vol. 6 , pp 147-176.

17. M. Miyata, M. Shibakami, S. Chirachanchai, K. Takemoto, N. Kasi, and K. Miki, Nature, 343, 446 (1990).

18. M. Miyata, K. Sada, S. Hori, and K. Miki, Mol. Cryst. Liq. Cryst., 219, 71 (1992).

19. K. Nakano, K. Sada, and M. Miyata, Mol. Cryst. Liq. Cryst., 276, 129 (1996).

20. K. Nakano, K. Sada, and M. Miyata, Progr. Colloid Polym. Sci., 106, 249 (1997).

21. K. Nakano, K. Sada, and M. Miyata, J. Chem. Soc., Chem. Commun., 989 (1996).

22. H. Nakano, "Molecular Graphics", Science House, Tokyo, 1987.

23. K. Miki, A. Masui, N. Kasai, M. Miyata, M. Shibakami, and K. Takemoto, J. Am. Chem. Soc., 110, 6594 (1988).

24. P. L. Johnson and J. P. Schaefer, Acta Crystallogr., B 28, 3083 (1972).

25. K. Miki, N. Kasai, M. Shibakami, K. Takemoto, and M. Miyata, J. Chem. Soc., Chem. Commun., 1757 (1991).

26. D. Blondin, J. Regis, and J. Prud'homme, Macromolecules, 7 , 187 (1974).

27. E. Giglio, in "Inclusion Compounds", J. L. Atwood, J. E. D. Davies, and D. D. MacNicol, Ed., Academic Press, London, 1984, vol. 2, p 207.

28. R. Popovitz-Biro, C.-P. Tang, H. C. Chang, M. Lahav, and L. Leiserowitz, J. Am. Chem. Soc., 107, 4043 (1985).

29. P. J. Rizkallah, M. M. Harding, P. F. Lindley, A. Aigner, and A. Bauer, Acta. Cryst., B 46, 262 (1990). 